power over the careers and reputations of others. Within the political systems of disciplines and specialisms, peer groups may serve as democratic controls, particularly in reviewing, but power tends to concentrate in very small networks.

Suggestive though it is, this short study is nevertheless only a preliminary excursion into the field. Becher restricts himself to élite institutions. His fieldwork was done in Britain and the United States, but he gives an undifferentiated account of the Anglo-American university world, although the national variations are surely very striking. A future study, more sensitive to the national character of academic enterprises, should also consider Dutch, German or Scandinavian universities, with their civil service cultures, or European think-tanks, like the Max-Planck Institutes, on which Nature has been publishing some unsettling ethnographic reports. A reading of Pierre Bourdieu's Homo Academicus, a dense and original recent study of the French academic system, will convince the foreigner that they do things very differently in France. For the purposes of Becher's argument, it is, for instance, noteworthy that the prestige hierarchy of disciplines diverges from the Anglo-Saxon model, and also that the leading research teams are to be found outside the university sector.

Becher does not draw together his scattered comments on the connections which might be made between the peculiarities of various academic tribes and the nature of the territories they inhabit. Here again a comparative approach would have suggested fresh questions. Are German physicists more like German economists in their career patterns and organizational hierarchies than they are like American physicists? Or is it something about physics, or economics, that is decisive? Professor Becher briefly discusses the different environments of the various disciplines - the market pressures on engineers, the professional demands made of lawyers and so forth. But these also vary between different national political systems and markets, as may be seen from the contrasting views of academic engineering in Britain and in Germany.

One important implication of the study is nevertheless clear. These various enterprises are not readily measured by the same criteria because they differ so markedly (and probably necessarily) in their goals, methods, work habits and relationships to the outside world. Bureaucrats will have to refine their measures of efficiency if they are to do justice to this diversity of academic society.

Adam Kuper is in the Department of Human Sciences, Brunel University, Uxbridge, Middlesex UB8 3PH, UK.

\section{Gossip value}

\section{Lewis Wolpert}

Life Among the Scientists: An Anthropological Study of an Australian Sclentific Community. By Max Charlesworth, Lyndsay Farrall, Terry Stokes and David Turnbull. Oxford University Press, Australia: 1989. Pp.304. Pbk A\$19.95. To be published in Britain and the United States next year.

A MEASURE of one's understanding of other groups is how well you appreciate their humour. This applies as much to scientists as any subset of people, for jokes and wit are a prominent feature of laboratory and institutional life. Yet humour is
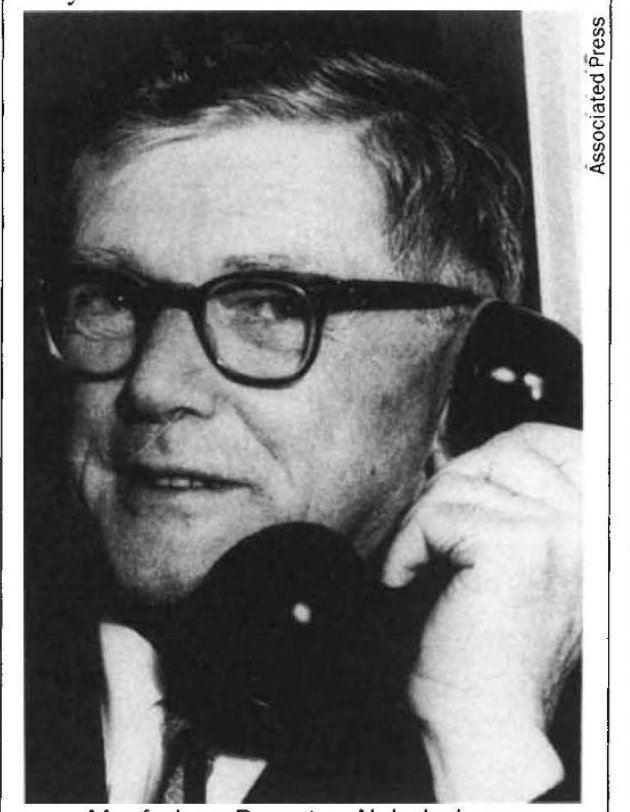

Macfarlane Burnet - Nobel winner.

not mentioned in this book. The scientists at the Walter and Eliza Hall Institute of Medical Sciences in Melbourne - the group considered - may of course be unusual, but a more likely explanation is that the social scientists who carried out this anthropological survey simply failed to understand much of what they were studying.

The authors, who have adopted the curious convention of writing in the first person, like a conflated committee, set out with the provisional hypothesis that scientific knowledge is socially "constructed'. This is a fashionable view among many sociologists of science and implies that science has rather little to do with the real world that scientists study, but instead is shaped by a complex set of social factors. This relativist stance is then used to argue that scientific knowledge has no particular virtue or validity. These authors take a more equivocal position but basically stick to this idea, and the possibility that science provides understanding of natural phenomena is virtually ignored.
The Walter and Eliza Hall Institute is very distinguished, its contributions to science covering a wide range of topics in molecular and cellular immunology. The first director (1944-1965), Sir Macfarlane Burnet, won a Nobel prize for his clonal selection theory and in the book there is an attempt to view him as a local hero whose social function is to legitimize a particular conception of science - the idea of an individual scientist making a discovery which revolutionizes the field. Burnet was hostile to molecular biology and his general style is contrasted with that of the current director, Sir Gus Nossal. But the analysis provides no insight into how Burnet came to make his great discovery or into the basis of his antipathy to molecular biology. It may not have been his dislike of complex apparatus and expensive equipment, as Charlesworth and his colleagues suggest, but rather his inability to see the power of molecular biology. He simply did not believe that it would be possible to understand cells in molecular terms - they were, for him, impossibly complex.

One of the main conclusions of the study is how large a part 'power' plays in the scientific process, for example in what the authors call the legitimization of molecular biology. They are persuaded that Foucault's insight is "profoundly true", namely that the establishment of specific discourses - ways of speaking and thinking - also provides access to power and control over the objects of those discourses. For them "the new model that came to dominate biology after the discovery of DNA only became established after a good deal of politicking and propaganda", in which 'public relations' used by scientists had a large part. The brief analysis of this period is most unsatisfactory and fails to take into account the change in paradigm from metabolism to information. The authors also do not understand the revolution molecular biology caused, and instead concentrate on the idea that molecular biology was a philosophical movement based on the conviction that all biology could be explained in terms of physics and chemistry. Thus it is said that Crick used Schrödinger's name to legitimize his reductionist approach. Of course there was evangelizing and politicking but none of that would have been effective had molecular biology not provided fundamental new insights. Moreover, scientists are aware of these issues and the nature of scientific politics, fashions and power. That's what they often gossip about.

There is a touching, but nevertheless irritating naivety to the conception of science purveyed in the book. For example, the authors are apparently appalled by "the contradiction between the ideal norms of science, that scientific knowledge should be disinterested 
and the spirit of competitive individualism", and imply that competition between scientists (the " "winner takes all' ethos") is something new. Yet one of the rewards in science has always been priority in discovery - are Charlesworth et al. really unaware of the great historical controversies, such as that between Newton and Leibniz over who discovered the calculus? And where do these 'ideals' and 'norms' come from? These really important social constructs are neither questioned nor analysed.

Competitiveness is the subject of a section of the book dealing with immunoparasitology and the quest for a malaria vaccine. Nossal's refutation of their views, which they quote at length, seems to have made no impression. Nossal recognizes competitiveness but emphasizes the tremendous amount of collaboration that science involves. "Now the question is, does the winner take all? Of course not! The peer group is not stupid. ... The second or third in the race may not win the Nobel prize, but there are plenty of important subsidiary rewards".

This book was intended to convey a sense of the "life-world" of a group of scientists as well as some idea of how that world is "constructed". In this it fails. Much of the description is like that found in an annual report, and any half-decent journalist would have done a far better job. Rather, its value lies in what it reveals about anthropology and social science. Did the authors bring any new insights or techniques from their discipline? There is hardly a word about how the study was carried out or over what period. Did they listen to the gossip? All sorts of important questions are not touched upon. How, for example, does the Institute deal with scientists that are no longer productive; how are resources distributed; to what extent is the research directed; were there different styles of sciences; what are the rewards that scientists seek? An apparent desire for objectivity seems to have killed any curiosity, and any interest.

What, for example, can one say of the following? "What impresses me more and more about a good deal of science at the Institute is the concentration on 'getting data" " and "the idea of data generation seems to me to be a crucial feature of science and is often overlooked. The laboratory is a kind of data factory". No one should be surprised that data are important for biologists, while the metaphor of a "data factory" is plain fatuous. If this is all that anthropology has to offer for studying other groups, then the result is depressing.

Lewis Wolpert is in the Department of Anatomy and Developmental Biology, University College and Middlesex School of Medicine, Windeyer Building, Cleveland Street, London W1P 6DB, UK

\section{Cut in production}

Norman Myers

Tropical Forests: Botanical Dynamics, Speciation and Diversity. Edited by L. B. Holm-Nielsen, I. C. Nielsen and H. Balslev. Academic:1989. Pp.380. £29.50 $\$ 49.50$.

Tropical Rain Forest Ecosystems: Biogeographical and Ecological Studies. Ecosystems of the World 14B. Edited by H. Lieth and M. J. A. Werger. Elsevier: 1989. Pp. 713. Dfl. $475, \$ 250$.

The Fate of the Forest: Developers, Destroyers and Defenders of the Amazon. By S. Hecht and A. Cockburn. Verso, London:1989. Pp.256. £16.95, \$24.95 Saving the Tropical Forests. By Judith Gradwohl and Russell Greenberg. Island Press, Washington, DC/Earthscan, London:1989. Pp.214. Hbk \$24.95; pbk £6.95.

WE ARE being overwhelmed by books on tropical forests, some of them less than whelming. The rush to publication reflects the recent burst of interest in the forests as we become aware of their impending demise and their intrinsic wealth.

One of the reasons why we have not done a better job of safeguarding the forests is that we understand all too little of what we are dealing with - at least as compared with savannahs, grasslands, temperate woodlands and tundras - or of what is at stake. There is still only a sparse selection of solid scientific writings on the forests' makeup, their biotic richness, their ecological complexity, their community structures, their dynamic interactions and - above all - their relationships to the human enterprise. For example, we have only a vague notion of how biotically diverse the forests are. Just this year Professor Steve Hubbell of Princeton University revealed that a 50 -hectare plot in Peninsular Malaysia contains over 800 species of woody plant, or as many as in all of North America. And when we finally gain a true grasp of the forests' ultimate richness, we shall finally gain a true realization of how far we have to go before we understand their diverse interactions.

Tropical Forests: Botanical Dynamics, Speciation and Diversity provides an abundance of the types of data and analyses that must underpin programmes for conservation and sustainable use. The opening section on forest dynamics appraises the physical factors such as soil and water regimes, together with patterns of tree distribution, gap-phase dynamics, canopy composition and dynamic stability of forest structures overall. There follow extended sections on speciation and diversity, primary and secondary formations, and community dynamics, before the book winds up with a retrospect-and- prospect summation. All of the chapters are authoritative to a degree - among the contributors are Gentry, Halle, Hartshorn, Mori, Oldeman, Polhill and Raven - and they challenge the reader with the thought that tropical forests remain virtually a terra nova to modern science.

Tropical Rain Forest Ecosystems, published in Elsevier's Ecosystems of the World series, reflects the experiences of another lengthy list of luminaries Bruenig, Ewel, Golley, Janzen, Jordan, Kartawinata, Kira, Prance, Sanchez and several others. The book's structure is similar to that of the first. It starts with the physical environment (notably climate among other limiting factors), moves on to tree architecture, taxonomy and classification, then to accounts of interactions such as epiphytism and symbiotic relationships, which lead into a consideration of some plant categories such as lianas, bryophytes and lichens, as well as of mammal categories such as primates, bats and flying insects. These expository reviews are interspersed with assessments of the three main tropical forest regions, and of a number of the countries concerned.

These two books make plain how few scientific answers we yet possess, and how far we are from even asking all the right questions about tropical forests. Regrettably and remarkably, however, neither of them says much about the actual rate at which the forests are disappearing, even though there is now a host of remotesensing and other inventorying technologies that can provide the relevant data. I estimate that during the 1980 s deforestation has accelerated by roughly 50 per cent, not only in Brazil but in Bolivia, the Ivory Coast, Burma, Thailand, Eastern Malaysia and the Philippines. Incidentally, the United Nations agency charged with responsibility for tropical forests, the Food and Agriculture Organization, asserts there has been no evidence of any increase in the deforestation rate during the $1980 \mathrm{~s}$ - and it does not intend to publish a revision of its 1982 report before 1992 at the earliest.

Nor do the two books attempt any analysis of why the forests are disappearing so rapidly. The editors might legitimately claim that they are natural-science assessments. All the same, it seems strange that in 1989 they should include no multidisciplinary evaluation of the whys and wherefores of deforestation - the economic, political, social and institutional factors at work. One could argue that it is partly because of this deficiency in the past that the forests are now disappearing; ecologists and economists have been far too reluctant to make common cause in presenting an integrated assessment of what the forests amount to and hence how they can be safeguarded.

All the more welcome, then, is the third 